\title{
Aryl hydrocarbon receptor pathway activation enhances gastric cancer cell invasiveness likely through a c-Jun-dependent induction of matrix metalloproteinase-9
}

\author{
Tie-Li Peng ${ }^{\dagger}$, Jie Chen ${ }^{\dagger}$, Wei Mao, Xin Song and Min-Hu Chen*
}

Address: Department of Gastroenterology, the First Affiliated Hospital of Sun Yat-Sen University, Guangzhou, PR China

Email: Tie-Li Peng - pengtl@163.com; Jie Chen - chenjie7209@yahoo.com; Wei Mao - mao-wei@263.net;

Xin Song - songxin68@yahoo.com.cn; Min-Hu Chen* - Chenminhu@vip.163.com

* Corresponding author †Equal contributors

Published: 16 April 2009

BMC Cell Biology 2009, 10:27 doi:10.1/86/147|-2/21-10-27
Received: 15 December 2008

Accepted: 16 April 2009

This article is available from: http://www.biomedcentral.com/I47I-2/2I//0/27

(c) 2009 Peng et al; licensee BioMed Central Ltd.

This is an Open Access article distributed under the terms of the Creative Commons Attribution License (http://creativecommons.org/licenses/by/2.0), which permits unrestricted use, distribution, and reproduction in any medium, provided the original work is properly cited.

\begin{abstract}
Background: Abberant aryl hydrocarbon receptor (AhR) expression and AhR pathway activation are involved in gastric carcinogenesis. However, the relationship between AhR pathway activation and gastric cancer progression is still unclear. In present study, we used 2,3,7,8-tetrachlorodibenzopara-dioxin (TCDD), a classic and most potent ligand of AhR, to activate AhR pathway and investigated the effect of AhR pathway activation on human gastric cancer AGS cell invasion and explored the corresponding mechanism.
\end{abstract}

Results: To determine whether AhR pathway can be activated in AGS cells, we examined the expression of CYPIAI, a classic target gene of AhR pathway, following TCDD exposure. RT-PCR and western blot analysis showed that both CYPIAI mRNA and protein expression were increased in a dose-dependent manner following TCDD treatment and AhR antagonist resveratrol (RSV) could reverse this TCDD-induced CYPIAI expression. To determine whether TCDD treatment of AGS cells results in an induction of MMP-9 expression, we detected MMP-9 mRNA using RT-PCR and detected MMP-9 enzymatic activity using gelatin zymography. The results showed that both MMP-9 mRNA expression and enzymatic activity were gradually increased with the concentration increase of TCDD in media and these changes could be reversed by RSV treatment in a dose-dependent manner. To examine whether AhR activation-induced MMP-9 expression and activity in AGS cells results in increased migration and invasion, we performed wound healing migration assay and transwell migration and invasion assay. After TCDD treatment, the migration distance and the migration and invasion abilities of AGS cells were increased with a dose-dependent manner. To demonstrate AhR activation-induced MMP-9 expression is mediated by c-Jun, siRNA transfection was performed to silence c-Jun mRNA in AGS cells. The results showed that MMP-9 mRNA expression and activity in untreated control AGS cells were very weak; After TCDD ( $10 \mathrm{nmol} / \mathrm{L})$ treatment, MMP-9 mRNA expression and activity were significant increased; This TCDD-induced MMP-9 expression and activity increase could be abolished by c-Jun siRNA transfection.

Conclusion: AhR pathway activation enhances gastric cancer cell invasiveness likely through a cJun-dependent induction of MMP-9. Our results provide insight into the mechanism and function of the AhR pathway and its impact on gastric cancer progression. 


\section{Background}

Aryl hydrocarbon receptor (AhR) is a ligand-activated transcription factor of the basic helix-loop-helix/Per-ArntSim family. In the absence of ligand, AhR is present in the cytosol in the form of a complex with two chaperone Hsp90s, a smal protein (p23), and an immunophilin-like protein (XAP2) [1,2]. Upon ligand such as 2,3,7,8-tetrachlorodibenzo-para-dioxin (TCDD, the most potent and classical exogenous AhR ligand) binding, the chaperon proteins dissociate and AhR translocate into the nucleus to form a heterodimer with its partner molecule aryl hydrocarbon receptor nuclear translocator (ARNT) $[3,4]$. This heterodimer binds to the specific DNA region termed dioxin response element (DRE), which has a core sequence of 5'-TNGCGTG-3', and thereby activates a battery of genes expression [5-7].

Historically, studies of AhR pathway have focused on the transcriptional regulation of genes encoding xenobiotic metabolizing enzymes such as cytochrome P450 enzymes [8]. Recent studies demonstrated a close relationship between AhR and mammary gland tumorigenesis [7,9]. AhR gene polymorphisms have been linked to an increased risk of lung and breast cancers [10,11]. Increased expression of AhR has been reported in lung, breast, and pancreatic cancers in humans [7,12,13]. Studies also suggest that constitutively active AhR may promote hepatocarcinogenesis in mice [14]. These data indicated a close relationship between AhR and tumorigenesis. However, the relationship between AhR and tumor progression is not clear.

Tumor cells invasion and metastasis is a complicated process among which degradation of extracellular matrix (ECM) and basement membrane is a crucial step. Tumor invasion and metastasis relies on the expression of matrix metalloproteinases (MMPs) to destroy the ECM and basement membrane to allow cell migration. MMPs are a group of zinc dependent metallopeptidases [15-17]. Matrix metalloproteinase-9 (MMP-9) is one of the type IV collagenase/gelatinases, which degrade basement membrane collagens and gelatins [16]. MMP-9 is widely associated with tumor invasion and metastasis [17]. The synthesis of MMP-9 is regulated by several growth factors, cytokines and hormones [16,18]. Recent study linked TCDD-associated lesions with aberrant matrix metabolism [8]. Microarray data demonstrate that TCDD/AhR alter expression of genes involve in matrix metabolism and deposition [8]. Villano et al [19] and Haque et al [18] reported that AhR agonist TCDD could induce MMP-9 expression in huamn melanoma cells and prostate cancer cells. These studies suggest that the MMP-9 expression may be a common endpoint for activation of the AhR pathway $[8,19]$.
Gastric cancer is the fourth most common malignancy and the second most frequent cause of cancer-related death in the world [20]. Gastric cancer cells invasion and metastasis often lead to a poor prognosis. Several studies linked AhR pathway activation to gastric carcinogenesis. Chen et al found increased expression of AhR in two human gastric cancer cell lines (RF1 and RF48) by microarray analysis [21]. Ma et al reported that concurrent expression of AhR and CYP1A1 is correlated with gastric cancer development [22]. Andersson et al found that constitutively activated AhR could induce stomach tumors in a transgenic mouse model [23]. In another of our studies, we found that AhR expression and nuclear translocation were significant higher in gastric cancer than in premalignant lesions and normal gastric mucosa [24]. However, the relationship between AhR pathway activation and gastric cancer invasion and metastasis is still not clear. Therefore, we investigated the effect of AhR pathway activation on human gastric cancer cells. Our data presented here demonstrate that AhR pathway can be activated in gastric cancer AGS cells and AhR pathway activation in AGS cells induces MMP-9 expression and enhances AGS cells migration and invasion activity. Furthermore, our data show that this AhR activation-induced MMP-9 expression is mediated by c-Jun.

\section{Results and discussion \\ AhR pathway activation in AGS cells}

In another of our studies we have demonstrated that there was a high level of AhR expression in AGS cells [24]. To determine whether AhR pathway can be activated in this cell line, we examined the expression of Cytochrome P450 1A1 (CYP1A1), a classic target gene of AhR pathway, following AhR agonist TCDD exposure. RT-PCR and western blot analysis showed that both CYP1A1 mRNA (Fig. 1A) and protein (Fig. 1B) expression in AGS cells were increased in a dose-dependent manner following TCDD treatment. To determine whether this TCDD-induced CYP1A1 expression is AhR-dependent, AhR antagonist resveratrol (RSV) was used to block AhR pathway. As shown in Fig. 1C and 1D, RSV could reverse TCDDinduced CYP1A1 expression in a dose-dependent manner. These data demonstrated that AhR pathway can be activated in AGS cells by TCDD.

\section{AhR pathway activation in AGS cells induce MMP-9 expression}

Previous studies have shown that in several cancer cells, AhR agonist TCDD exposure activates MMP-9 gene expression $[18,19]$. In order to determine whether TCDD treatment of AGS cells results in an induction of MMP-9 expression, we detected MMP-9 mRNA using RT-PCR following TCDD exposure. As shown in fig. 2A, MMP-9 mRNA expression was induced in a dose-dependent man- 


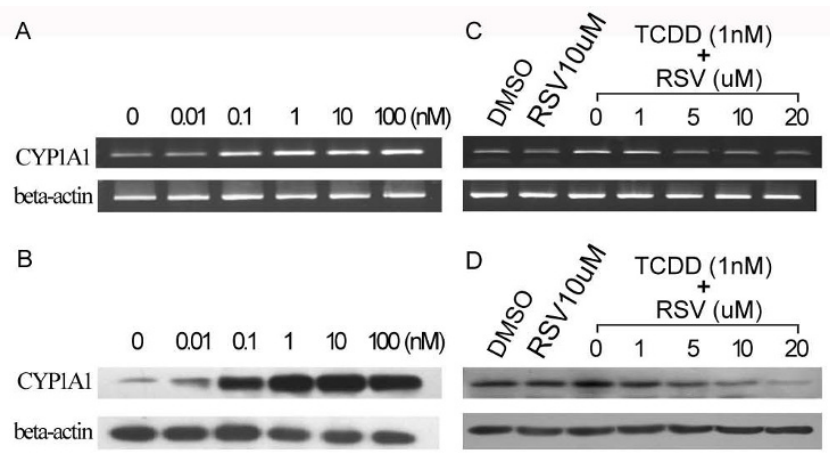

Figure I

AhR agonist TCDD and AhR antagonist RSV regulated CYPI AI I expression in AGS cells. After different concentrations (as shown above) of TCDD treatment for 24 hours, (A) RT-PCR analysis of CYPIAI mRNA expression in a concentration-response. (B) Western blot analysis of CYPIAI protein expression in a concentration-response. After co-treatment with TCDD (I nM) and RSV (at different concentrations as shown above) for 24 hours, (C) mRNA expression of CYPIAI was detected by RT-PCR. (D) Protein expression of CYPIAI was detected by Western blot.

ner following TCDD treatment. To examine the role of the AhR pathway in mediating TCDD-induced MMP-9 expression in AGS cells, cultures were co-treated with TCDD and the AhR antagonist resveratrol. Co-treatment with resveratrol abolished TCDD-induced MMP-9 expression (fig. 2C) demonstrated that TCDD-activation of MMP-9 expression is dependent on the AhR pathway.

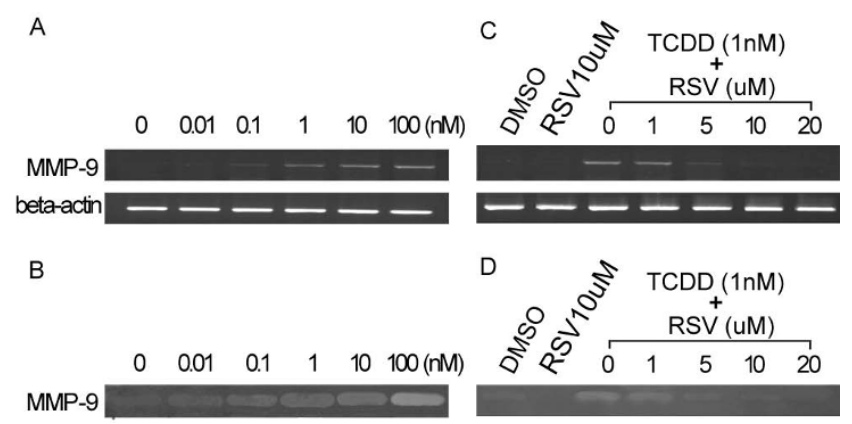

Figure 2

AhR agonist TCDD and AhR antagonist RSV regulated MMP-9 expression and activity in AGS cells. After different concentrations (as shown above) of TCDD treatment for 24 hours, (A) RT-PCR analysis of MMP-9 mRNA expression in a concentration-response. (B) Gelatin zymography analysis of MMP-9 protein activity in a concentration-response. After co-treatment with TCDD (I nM) and RSV (at different concentrations as shown above) for 24 hours, (C) mRNA expression of MMP-9 was detected by RTPCR. (D) Protein activity of MMP-9 was detected by gelatin zymography.
Above data indicate that AhR pathway activation in AGS cells induces MMP-9 mRNA expression. In most cell types, the gene transcription of MMP-9 is inducible, and after translation the enzyme is immediately secreted and activated through the cysteine-switch mechanism [25]. To determine whether these changes in gene expression following AhR pathway activation result in changes in MMP9 enzymatic activity, we performed gelatin zymography. The results showed that MMP-9 activity in media is gradually increased with the concentration increase of TCDD in media (fig. 2B) and these changes could be reversed by resveratrol treatment in a dose-dependent manner (fig. 2D). These data demonstrate that AhR pathway activation-induced increase in MMP-9 expression correlates with an increase in MMP-9 activity.

\section{AhR pathway activation enhances AGS cells migration and invasion}

MMP-9 is one of the type IV collagenase/gelatinases that can degrade ECM components. MMP-9 is widely associated with tumor invasion and metastasis [17]. Studies have demonstrated a significant correlation between MMP-9 expression and invasiveness and lymph node metastasis of gastric carcinomas [26-28]. To examine whether AhR activation-induced MMP-9 expression and activity in AGS cells results in increased migration and invasion, we performed wound healing migration assay and transwell migration and invasion assay. After TCDD treatment, the migration distance of AGS cells was significantly increased with a dose-dependent manner when compared with control cells $(\mathrm{P}<0.01)$ (fig. 3A). Transwell results showed a significant increase of migration (fig. $3 \mathrm{~B}$ ) and invasion (fig. 3C) abilities of AGS cells when the cells were incubated with TCDD in concentrations from 0.1
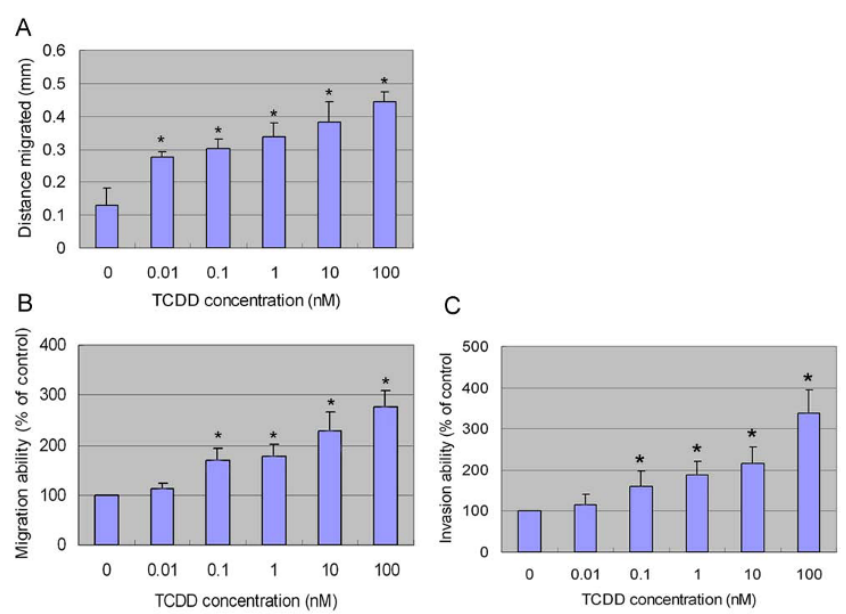

Figure 3

The effect of AhR agonist TCDD on AGS cells migration and invasion. (A) Wound healing migration assay. (B) Transwell migration assay. (C) Transwell invasion assay. 
$\mathrm{nmol} / \mathrm{L}(\mathrm{P}<0.01)$ to $100 \mathrm{nmol} / \mathrm{l}(\mathrm{p}<0.01)$. no significant effect on the migration and invasion was found at TCDD concentration $<0.1 \mathrm{nmol} / \mathrm{l}(\mathrm{p}>0.05)$. These results demonstrated that AhR pathway activation enhances gastric cancer AGS cells migration and invasion. Degradation of ECM and basement membrane is an essential step in tumor invasion and metastasis. It involves the action of matrix metalloproteinases (MMPs). Our study demonstrated that AhR pathway activation could induce MMP-9 expression and enzymatic activity, and promote AGS cells migration and invasion. Other studies indicated that AhR pathway activation could induce a variety of MMPs expression $[19,29]$. AhR pathway activation enhances gastric cancer AGS cells migration and invasion may be also due to other MMPs expression besides MMP-9 expression.

\section{c-Jun mediated MMP-9 expression induced by $A h R$ pathway activation}

The mechanism of TCDD-induced changes in MMP-9 expression is not entirely clear. Recent studies reported that TCDD can induce c-Jun expression [30,31] and c-Jun is a target gene of AhR pathway [8]; the promoter sequence in the 5'-flanking region of human MMP-9 gene contains c-Jun binding sites [16] and c-Jun can induced MMP-9 expression [32]; the transcription activity of c-Jun is significant enhanced in gastric cancer [33]. Basing on these study results, we proposed a hypothesis that TCDDinduced MMP-9 expression in AGS cells is mediated by cJun. To demonstrate this hypothesis, we first detected the c-Jun expression in AGS cells following TCDD treatment, and found that both c-Jun mRNA (fig. 4A and 4C) and

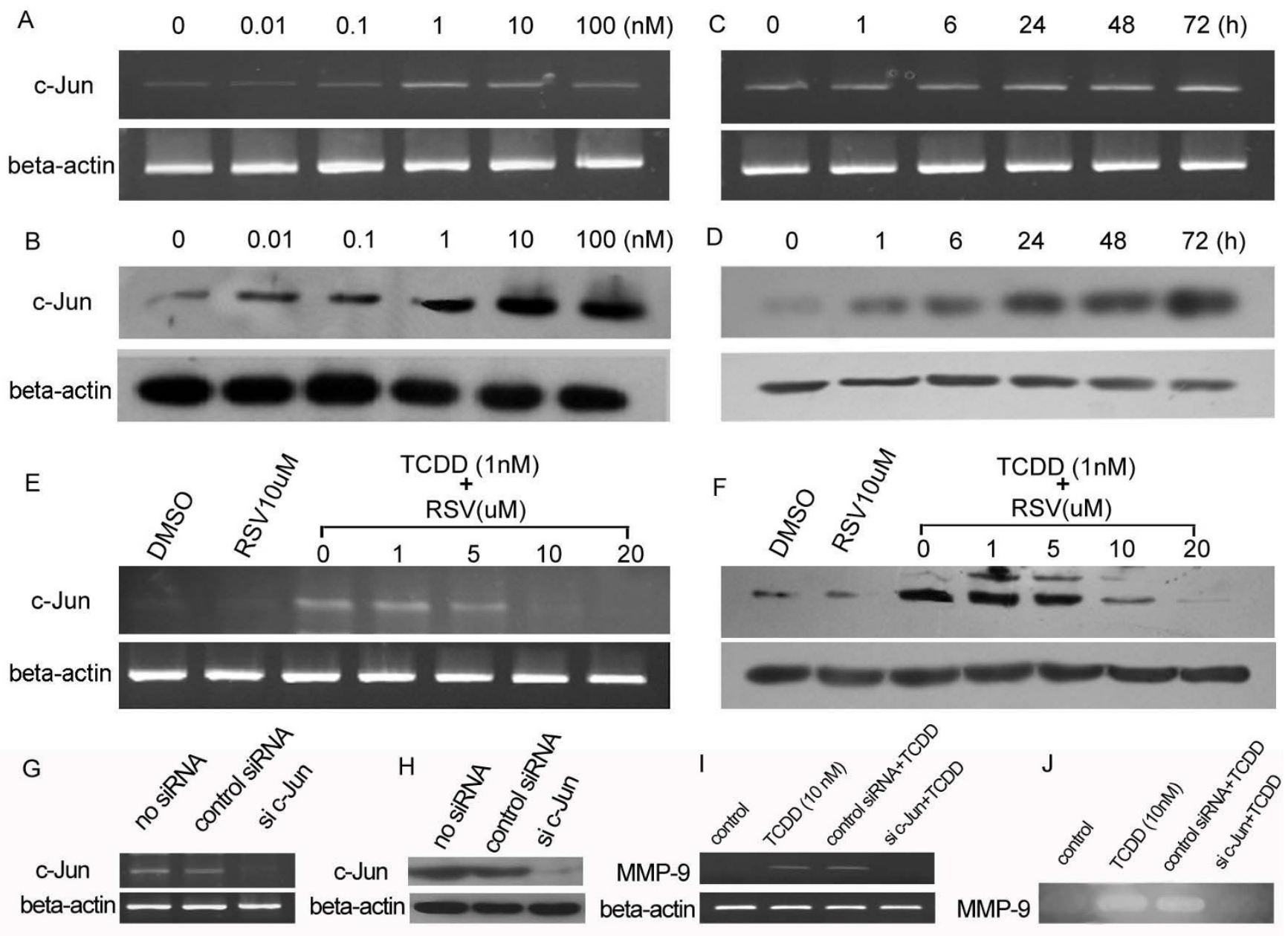

Figure 4

c-Jun mediates TCDD-induced MMP-9 expression and activity. (A) TCDD induces c-Jun mRNA expression in a dosedependent manner. (B) TCDD induces c-Jun protein expression in a dose-dependent manner. (C) TCDD induces c-Jun mRNA expression in a time-dependent manner. (D) TCDD induces c-Jun protein expression in a time-dependent manner. (E) RSV reverses TCDD-induced c-Jun mRNA expression. (F) RSV reverses TCDD-induced c-Jun protein expression. (G) c-Jun siRNA silences c-Jun mRNA expression. $(\mathrm{H}) \mathrm{c}$-Jun siRNA silences c-Jun protein expression. (I) c-Jun siRNA inhibits TCDD-induced MMP-9 mRNA expression. (J) c-Jun siRNA inhibits TCDD-induced MMP-9 activity increase. 
protein (fig. 4B and 4D) expression in AGS cells were increased in a dose (fig. $4 \mathrm{~A}$ and $4 \mathrm{~B}$ ) and time (fig. 4C and 4D) dependent manner following TCDD treatment, and this TCDD-induced c-Jun expression could be reserved by AhR antagonist resveratrol (fig. 4E and 4F). Above data demonstrated that c-Jun is a target gene of AhR pathway in AGS cells. To further demonstrate that c-Jun can mediate TCDD-induced MMP-9 expression, siRNA transfection was performed to silence c-Jun mRNA in AGS cells. The results demonstrated that c-Jun siRNA (final concentration $50 \mathrm{nmol} / \mathrm{L}$ ) transfection almost completely abolished c-Jun expression in AGS cells both in mRNA level (fig. 4G) and in protein level (fig. 4H). Therefore, after cJun siRNA transfection for 48 hours, AGS cells were treated with TCDD at concentration $10 \mathrm{nmol} / \mathrm{L}$ for 24 hours, cell pellet and culture media were collected, and MMP-9 mRNA expression and activity were measured. As shown in fig. 4I and 4J, MMP-9 mRNA expression and activity in untreated control AGS cells were very weak; After TCDD (10 nmol/L) treatment, MMP-9 mRNA expression and activity were significant increased; This TCDD-induced MMP-9 expression and activity increase could be abolished by c-Jun siRNA transfection and not be influenced by control siRNA transfection. Above data demonstrated that c-Jun mediated MMP-9 expression induced by AhR pathway activation in AGS cells.

\section{Conclusion}

In conclusion, the present study demonstrate that AhR pathway can be activated in gastric cancer AGS cells and AhR pathway activation induces MMP-9 expression and activity which ultimately contributes to AGS migration and invasion in vitro. Furthermore, our data show that this AhR activation-induced MMP-9 expression is mediated by c-Jun. Because degradation of ECM and basement membrane is an essential step in tumor invasion and metastasis, our results provide insight into the mechanism and function of the AhR pathway and its impact on these processes during gastric cancer progression.

\section{Methods \\ Cell culture}

Gastric cancer cell line AGS was obtained from the American Type Culture Collection (ATCC, Rockville, MD), and was maintained in RPMI 1640 medium (Hyclone) supplemented with $2 \mathrm{mM}$ glutamine, 10\% fetal bovine serum (Hyclone), 100 units $/ \mathrm{ml}$ of penicillin, and $100 \mu \mathrm{g} / \mathrm{ml}$ of gentamycin. Cellular environment was maintained at 5\% $\mathrm{CO}_{2}$ and $37^{\circ} \mathrm{C}$. Cells were harvested from the exponential growth phase and total RNA and protein were prepared as described below.

\section{Treatment of cells}

TCDD and Resveratrol were purchased from Sigma Chemical Company (Bellefonte, PA, USA). After incubation for
24 hours, the cells were treated with TCDD at different concentrations $(0,0.01,0.1,1,10,100 \mathrm{nM})$ or TCDD (1 $\mathrm{nM})$ plus Resveratrol $(0,1,5,10,20 \mu \mathrm{M})$ for 24 hours, or treated with TCDD $(1 \mathrm{nM})$ for different time $(0,1,6,24$, 48,72 hours) respectively. All drugs were dissolved in dimethyl sulphoxide (DMSO). Control cells received $0.1 \%$ DMSO only.

\section{Small interfering RNA synthesis}

Small interfering RNAs (siRNAs) were synthesized and high-performance purified (Ribo Biotechnology, Guangzhou). c-Jun siRNAs (sense, CCAAGAACGUGACAGAUGA-dTdT; antisense, UCAUCUGUCACGUUCUUGG-dTdT) and control siRNAs (sense, AG GAG AUA UU UCGAGGCUU-dTdT; antisense, AAGCUCGAA AUA UC UCCU-dTdT), bearing no homology with any known human genes, were dissolved in RNase-free $\mathrm{ddH}_{2} \mathrm{O}$ to a final concentration of $20 \mu \mathrm{mol} / \mathrm{L}$.

\section{Small interfering RNA transfection}

Cells $\left(5 \times 10^{5}\right)$ were plated onto wells of six-well cell culture plates and allowed to adhere for 24 hours. Four microliters Lipofectamine2000 (Invitrogen) per well were added to serum-free Opti MEM (Invitrogen) for a final complexing volume of $250 \mu \mathrm{l}$, gently mixed, and incubated at room temperature for 5 minutes. Five microliters of siRNA solution per well were diluted with $250 \mu \mathrm{l}$ serum-free Opti MEM. Mix the diluted siRNA solution and the diluted Lipofectamine 2000 gently, and incubate at room temperature for 30 minutes. The Lipofectamine2000/siRNA complex was added into the wells containing $1500 \mu \mathrm{l}$ RPMI 1640 with $10 \%$ FBS and incubated in normal cell culture conditions. All of the assays were performed after 48 hours.

\section{RNA isolation and RT-PCR}

Total RNA of cells was extracted using the Quiagen RNeasy Mini Kit (Quiagen) according to the manufacturer's instructions. cDNA was synthesized with $1 \mu \mathrm{g}$ total RNA using reverse transcriptase, ReverTra AceTM (Toyobo Co, Osaka, Japan) under following condition: $30^{\circ} \mathrm{C}$ for 10 $\min , 42^{\circ} \mathrm{C}$ for $20 \mathrm{~min}, 99^{\circ} \mathrm{C}$ for $5 \mathrm{~min}$, and $4^{\circ} \mathrm{C}$ for 5 min. PCR of $\mathrm{CDNA}$ was carried out in a reaction mixture $(30 \mu \mathrm{l})$ containing $2 \mu \mathrm{l}$ of template cDNA, $2.5 \mathrm{mM} \mathrm{MgCl}_{2}$, $200 \mu \mathrm{M}$ dNTPs, $0.3 \mu \mathrm{M}$ primer 1 and 2, and 1 unit of Taq DNA polymerase (New England Biolabs). Amplification was performed using the following condition: $94^{\circ} \mathrm{C}$ for 5 min, followed by $25-32$ cycles (denature for $45 \mathrm{~s}$ at $94^{\circ} \mathrm{C}$, anneal for $30 \mathrm{~s}$, and extend for $30 \mathrm{~s}$ at $72^{\circ} \mathrm{C}$ ), and then $72^{\circ} \mathrm{C}$ for $7 \mathrm{~min}$. The details of primers, annealing temperature, amplification cycles, and PCR product size for each gene are listed in Table 1. The PCR products were electrophoresed on $1.5 \%$ agarose gel, stained with ethidium bromide, and visualized with an ultra-violet (UV) transilluminator. Band intensities in RT-PCR were quanti- 
Table I: Primer sequences and PCR amplification conditions

\begin{tabular}{|c|c|c|c|c|}
\hline Gene & Primers $\left(5^{\prime} \rightarrow 3^{\prime}\right)$ & Annealing temperature $\left({ }^{\circ} \mathrm{C}\right)$ & Cycles & Product size(bp) \\
\hline \multirow[t]{2}{*}{ CYPIAI } & s: CCATGTCGGCCACGGAGTT & 59 & 32 & 174 \\
\hline & A: ACAGTGCCAGGTGCGGGTT & & & \\
\hline \multirow[t]{2}{*}{ MMP-9 } & S: CAACATCACCTATTGGATCC & 52.5 & 37 & 480 \\
\hline & A: CGGGTGTAGAGTCTCTCGCT & & & \\
\hline \multirow[t]{2}{*}{ c-Jun } & S: TCAGACAGTGCCCGAGAT & 55.2 & 30 & 292 \\
\hline & A: CTGCGTTAGCATGAGTTGG & & & \\
\hline \multirow[t]{2}{*}{ Beta-actin } & S: CTCGCTGTCCACCTTCCA & 52 & 30 & 256 \\
\hline & A: GCTGTCACCTTCACCGTTC & & & \\
\hline
\end{tabular}

Abbreviations: $S$, sense primer; $A$, antisense primer

fied using Quantity One imaging analysis software. Band intensities of CYP 1A1, MMP-9 and c-Jun mRNA were normalized with corresponding band intensities of betaactin. Data was reported as mean $\pm \mathrm{SD}$.

\section{Western blot analysis}

Cell pellets were homogenized in a lysis buffer containing $20 \mathrm{mM}$ Hepes, $1 \mathrm{mM}$ EGTA, $50 \mathrm{mM} \beta$-glycerophosphate, $2 \mathrm{mM}$ Sodium orthovanadate, $10 \%$ Glycerol, $1 \%$ Triton $\mathrm{X}-100,1 \mathrm{mM}$ DTT, and $1 \times$ Protease Inhibitor Cocktail (Roche, Mannheim, Germany). Lysate was centrifuged at $13000 \mathrm{rpm}$ and $4^{\circ} \mathrm{C}$ for 10 minutes. The supernatant was the total cell lysate. Protein concentration was measured using the BCA protein assay kit (Pierce Chemical Co., Rockford, IL). Thirty micrograms of protein was loaded per lane, separated by $10 \%$ SDS-polyacrylamide gel electrophoresis, and transferred onto equilibrated polyvinylidene difluoride membrane by electroblotting. Membranes were blocked with TBS-T buffer containing $5 \%(\mathrm{w} / \mathrm{v})$ nonfat dry milk. AhR, CYP1A1, c-Jun and betaactin were detected for 2 hours using antibodies against AhR (SC-5579, Santa Cruz Biotechnology, working dilution 1:150), CYP 1A1 (AB1258, Chemicon International, working dilution 1: 500), c-Jun (SC-1694, Santa Cruz Biotechnology, working dilution 1:200) and beta-actin (\#4970, Cell Signaling Technology, working dilution 1: 1000). After secondary antibody incubation (working dilution 1: 2000), enhanced chemiluminescence (Pierce Biotechnology, Inc.) was determined by exposure to x-ray film. Band intensities in Western blot were quantified using Quantity One imaging analysis software. Band intensities of CYP $1 \mathrm{~A} 1$ and c-Jun were normalized with corresponding band intensities of beta-actin. Data was reported as mean $\pm \mathrm{SD}$.

\section{Gelatin zymography}

Media from TCDD treated cultures was electrophoresed on SDS-PAGE where the gel contains $0.1 \%(\mathrm{w} / \mathrm{v})$ gelatin. The gel was incubated overnight in a $\mathrm{Zn}^{2+}$ and $\mathrm{Ca}^{2+}$ containing buffer to allow the MMPs to regain their proper structure and degrade the gelatin in the gel. Clear white bands on the Coomassie stained gel are indicative of MMP activity. Band intensities were quantified using Quantity One imaging analysis software.

\section{Wound healing migration assay}

For the measurement of cell migration during wound healing, AGS cells were seeded in individual wells of a 6well culture plate. When the cells reached a confluent state, cell layers were wounded with a plastic micropipette tip having a large orifice. The medium and debris were aspirated away and replaced by $2.5 \mathrm{ml}$ of fresh serum-free medium which contained different concentrations of TCDD $(0,0.01,0.1,1,10,100 \mathrm{nM})$. Cells were photographed every $12 \mathrm{~h}$ after wounding by phase contrast microscopy. For evaluation of "wound closure," five randomly selected points along each wound were marked, and the horizontal distance of migrating cells from the initial wound was measured. Data was reported as mean \pm SD.

\section{Transwell migration and invasion assay}

Treated or untreated control cells were seeded in triplicate into the upper chamber of a Transwell insert (Corning, New York, NY, USA) in serum-free medium at a density of $1 \times 10^{5}$ per well. For migration assays, medium containing $5 \%$ serum was placed in the lower chamber to act as a chemoattractant, and cells were further incubated for $18 \mathrm{~h}$. Nonmigratory cells were removed from the upper chamber by scraping, and the cells remaining on the lower surface of the insert were stained using $0.1 \%$ crystal violet for 15 minutes. Cells were counted under a microscope. Invasion assays were done as for the migration assays described above, except inserts were precoated with the extracellular matrix (ECM) substitute Matrigel (BD Biosciences) and incubated over a 24 -h period. Each clone was plated in triplicate in each experiment and each experiment was repeated at least thrice. Cell migration (or invasion) ability $=$ (the cell number of treated group/the cell number of control group) $\times 100 \%$.

\section{Authors' contributions}

PTL and CJ contributed equally to this work; PTL and CJ performed research and wrote the paper. MW organized 
the figures and analyzed data. SX participated in the study design. $\mathrm{CMH}$ designed research and supervised the writing and organization process. All authors read and approved the final manuscript.

\section{Acknowledgements}

This work was supported by the following grants: the grants from National Natural Science Foundation of China (No. 30670949, No. 30671904 and No.3087 I 145), a grant awarded to new teacher from Chinese Ministry of Education (No.20070558288), a grant awarded to PhD supervisor from Chinese Ministry of Education (No. 200605580 I0), the grants from the Natural Science Foundation of Guangdong Province (No.5300767 and No.700164I).

\section{References}

I. Perdew GH: Association of the Ah receptor with the 90-kDa heat shock protein. I Biol Chem 1988, 263:13802-13805.

2. Petrulis JR, Hord NG, Perdew GH: Subcellular localization of the aryl hydrocarbon receptor is modulated by the immunophilin homolog hepatitis B virus $\mathbf{X}$-associated protein 2. J Biol Chem 2000, 275:37448-37453.

3. Hankinson O: Role of coactivators in transcriptional activation by the aryl hydrocarbon receptor. Arch Biochem Biophys 2005, 433:379-386.

4. Probst MR, Reisz-Porszasz S, Agbunag RV, Ong MS, Hankinson O: Role of the aryl hydrocarbon receptor nuclear translocator protein in aryl hydrocarbon (dioxin) receptor action. Mol Pharmacol 1993, 44:5।I-5I8.

5. Bradshaw TD, Trapani V, Vasselin DA, Westwell AD: The aryl hydrocarbon receptor in anticancer drug discovery: friend or foe? Curr Pharm Des 2002, 8:2475-2490.

6. Barouki R, Coumoul X, Fernandez-Salguero PM: The aryl hydrocarbon receptor, more than a xenobiotic-interacting protein. FEBS Lett 2007, 58I:3608-36I5.

7. Schlezinger JJ, Liu D, Farago M, Seldin DC, Belguise K, Sonenshein GE, Sherr DH: A role for the aryl hydrocarbon receptor in mammary gland tumorigenesis. Biol Chem 2006, 387: I I75-I I 87.

8. Hillegass JM, Murphy KA, Villano CM, White LA: The impact of aryl hydrocarbon receptor signaling on matrix metabolism: implications for development and disease. Biol Chem 2006, 387:1159-1173.

9. Marlowe JL, Puga A: Aryl hydrocarbon receptor, cell cycle regulation, toxicity, and tumorigenesis. J Cell Biochem 2005, 96: II74-1 I84

10. Kim JH, Kim H, Lee KY, Kang JW, Lee KH, Park SY, Yoon HI, Jheon SH, Sung SW, Hong YC: Aryl hydrocarbon receptor gene polymorphisms affect lung cancer risk. Lung Cancer 2007, 56:9-15.

II. LongJR, Egan KM, Dunning L, Shu XO, Cai Q, Cai H, Dai Q, Holtzman J, Gao YT, Zheng W: Population-based case-control study of AhR (aryl hydrocarbon receptor) and CYPIA2 polymorphisms and breast cancer risk. Pharmacogenet Genomics 2006, 16:237-243.

12. Lin P, Chang H, Tsai WT, Wu MH, Liao YS, Chen JT, Su JM: Overexpression of aryl hydrocarbon receptor in human lung carcinomas. Toxicol Pathol 2003, 31:22-30.

13. Koliopanos A, Kleeff J, Xiao Y, Safe S, Zimmermann A, Buchler MW, Friess $\mathrm{H}$ : Increased arylhydrocarbon receptor expression offers a potential therapeutic target for pancreatic cancer. Oncogene 2002, 21:6059-6070.

14. Moennikes O, Loeppen S, Buchmann A, Andersson P, Ittrich C, Poellinger L, Schwarz M: A constitutively active dioxin/aryl hydrocarbon receptor promotes hepatocarcinogenesis in mice. Cancer Res 2004, 64(14):4707-47I0.

15. St-Pierre Y, Van Themsche C, Esteve PO: Emerging features in the regulation of MMP-9 gene expression for the development of novel molecular targets and therapeutic strategies. Curr Drug Targets Inflamm Allergy 2003, 2:206-2I5.

16. Steen PE Van den, Dubois B, Nelissen I, Rudd PM, Dwek RA, Opdenakker G: Biochemistry and molecular biology of gelatinase B or matrix metalloproteinase-9 (MMP-9). Crit Rev Biochem Mol Biol 2002, 37:375-536.
17. Egeblad M, Werb Z: New functions for the matrix metalloproteinases in cancer progression. Nat Rev Cancer 2002, 2:16I-174.

18. Haque M, Francis J, Sehgal I: Aryl hydrocarbon exposure induces expression of MMP-9 in human prostate cancer cell lines. Cancer Lett 2005, 255:159-166.

19. Villano CM, Murphy KA, Akintobi A, White LA: 2,3,7,8-tetrachlorodibenzo-p-dioxin (TCDD) induces matrix metalloproteinase (MMP) expression and invasion in A2058 melanoma cells. Toxicol Appl Pharmacol 2006, 2 10:2 12-224.

20. Parkin DM, Bray F, Ferlay J, Pisani P: Global cancer statistics, 2002. CA Cancer J Clin 2005, 55:74- 108.

2I. Chen J, Rocken C, Klein-Hitpass L, Gotze T, Leodolter A, Malfertheiner $\mathrm{P}$, Ebert MP: Microarray analysis of gene expression in metastatic gastric cancer cells after incubation with the methylation inhibitor 5-aza-2'-deoxycytidine. Clin Exp Metastasis 2004, 21:389-397.

22. Ma JX, Zhang KL, Liu X, Ma YL, Pei LN, Zhu YF, Zhu L, Chen XY, Kong QY, Li H, Liu J: Concurrent expression of aryl hydrocarbon receptor and CYPIAI but not CYPIAI MspI polymorphism is correlated with gastric cancers raised in Dalian, China. Cancer Lett 2006, 240:253-260.

23. Andersson P, McGuire J, Rubio C, Gradin K, Whitelaw ML, Pettersson S, Hanberg A, Poellinger L: A constitutively active dioxin/aryl hydrocarbon receptor induces stomach tumors. Proc Natl Acad Sci USA 2002, 99:9990-9995.

24. Peng TL, Chen J, Mao W, Liu X, Tao Y, Chen LZ, Chen MH: Potential therapeutic significance of increased expression of aryl hydrocarbon receptor in human gastric cancer. World J Gastroenterol 2009, I 5: 1719-1729.

25. Van Wart HE, Birkedal-Hansen H: The cysteine switch: a principle of regulation of metalloproteinase activity with potential applicability to the entire matrix metalloproteinase gene family. Proc Natl Acad Sci USA 1990, 87:5578-5582.

26. Zhang $\mathrm{S}$, Li $Y$, Lin JY, Lin $\mathrm{H}$ : Imbalance between expression of matrix metalloproteinase-9 and tissue inhibitor of metalloproteinase- $I$ in invasiveness and metastasis of human gastric carcinoma. World J Gastroenterol 2003, 9:899-904.

27. Kabashima A, Maehara Y, Kakeji Y, Baba H, Koga T, Sugimachi K: Clinicopathological features and overexpression of matrix metalloproteinases in intramucosal gastric carcinoma with lymph node metastasis. Clin Cancer Res 2000, 6:358I-3584.

28. Torii A, Kodera Y, Uesaka K, Hirai T, Yasui K, Morimoto T, Yamamura $Y$, Kato T, Hayakawa T, Fujimoto N, Kito T: Plasma concentration of matrix metalloproteinase 9 in gastric cancer. $\mathrm{Br} J$ Surg 1997, 84: I33-136.

29. Murphy KA, Villano CM, Dorn R, White LA: Interaction between the aryl hydrocarbon receptor and retinoic acid pathways increases matrix metalloproteinase-I expression in keratinocytes. J Biol Chem 2004, 279:25284-25293.

30. Hoffer A, Chang CY, Puga A: Dioxin induces transcription of fos and jun genes by $A h$ receptor-dependent and -independent pathways. Toxicol Appl Pharmacol 1996, I 41:238-247.

31. Weiss C, Faust D, Dürk H, Kolluri SK, Pelzer A, Schneider S, Dietrich $C$, Oesch F, Göttlicher M: TCDD induces c-jun expression via a novel Ah (dioxin) receptor-mediated p38-MAPK-dependent pathway. Oncogene 2005, 24:4975-4983.

32. Smith LM, Wise SC, Hendricks DT, Sabichi AL, Bos T, Reddy P, Brown PH, Birrer MJ: cJun overexpression in MCF-7 breast cancer cells produces a tumorigenic, invasive and hormone resistant phenotype. Oncogene 1999, 18:6063-6070.

33. Shibata J, Murakami K, Aoyagi Y, Oie S, Hashimoto A, Suzuki K, Sano $M$, Wierzba TT, Yamada Y: The induction of apoptosis and inhibition of AP-I activity by TAC-I 0 I (4-[3,5-bis(trimethylsilyl) benzamido] benzoic acid) may result in life prolonging effect in animals bearing metastasizing cancer. Anticancer Res 2000, 20:3583-3590. 